\title{
Extremum Seeking Control applied to a model of the Hall-Héroult Aluminium process *
}

\author{
Pierre de Lamberterie* Boris I. Godoy ${ }^{* *}$ James S. Welsh* \\ * School of Electrical Eng.\& Computer Science \\ The University of Newcastle, Callaghan NSW 2308, Australia \\ ** Centre for Complex Dynamic Systems and Control \\ The University of Newcastle, Callaghan NSW 2308, Australia
}

\begin{abstract}
This paper examines the potential improvement in an aluminium production process using Extremum Seeking Control, to maintain operational conditions for temperature in a desired range. The proposed strategy applied to the aluminium process is simple, requiring little knowledge of the dynamics associated with the temperature of the process. Simulation results show that the proposed strategy for this process works well, obtaining good control of temperature, with small actuator movements.
\end{abstract}

Keywords: aluminium process, extremum seeking control, process modelling, nonlinear control

\section{INTRODUCTION}

The production of aluminium is important given the many applications of this metal in diverse areas. For example, aluminium is used in the automotive industry because of its strength and lighter weight as compared to other metals. Furthermore, aluminium is important in buildings and housing for its inherent properties to resist corrosion (Dwight, 1999).

Aluminium, unlike other metals, is not mined in its raw state. It has to be processed before it can be used. A typical process used to produce aluminium is the so-called HallHéroult process, which utilizes electrolysis to produce the metal.

The Hall-Héroult process is well-known and nowadays dominates the way aluminium is produced. Even though it has been used for many years, the Hall-Héroult process has some disadvantages. The main disadvantage is that the process consumes a large amount of energy because the temperature at which the chemical reactions occur are quite high, around $1010\left({ }^{\circ} \mathrm{C}\right)$. However, this nominal temperature can be lowered by the addition of other components to the cell (or pot) where the electrolysis occurs.

The Hall-Héroult process is considered to be a mature process in terms of control. In fact, the control of energy input to the process is accomplished in as many ways as the number of smelters around the world (Kolas and Store, 2009). The key strategy of the controllers is to reduce the variation of the controlled signals, achieving in this way more consistent operations with reduced energy consumption.

\footnotetext{
^ Corresponding author B.I. Godoy, e-mail: boris.godoy@newcastle. edu.au
}

In the present work, we use Extremum Seeking Control (ESC) to improve the temperature control in the electrolysis process. This control strategy has received increased attention in recent years (Ariyur and Krstić, 2003), although the application of ESC started a long time ago, (see e.g. Blackman, 1962). ESC has been traditionally applied to systems where there are no models, or existing models are unreliable or difficult to obtain. In recent works, ESC has also been used to find unknown parameters in nonlinear models, where an explicit structure for the objective function is required (Guay and Zhang, 2003). The main idea of ESC is to find the input of the system which maximizes (or minimizes) a nonlinear function. In this context, the application of ESC to the Hall-Héroult process is justified since the process shows a maximum in the current efficiency, which depends upon temperature and other variables such as composition of the ore, density and cell design (Grjotheim et al., 1982, p.336).

In this paper, ESC is used to control the temperature to obtain the value that gives maximum current efficiency in the electrolysis process. A simulation of ESC is carried out on a simplified model of the electrolysis (Drengstig, 1997), which is derived from physical principles. We modify the model as explained in Section $\S 4$, using only the part of it which is focused on the bath of the electrolysis cell, where the temperature dynamics and chemical reactions take place.

Our control strategy takes into consideration the strong coupling between acidity and temperature, a phenomena called temperature-acidity correlation, which is deeply discussed in Desclaux (1987); Salt (1990). Hence, we carry out a control strategy including both outputs. Temperature control is implemented by using ESC, and acidity control is implemented by using a PID controller.

The results obtained in this paper indicates that ESC is a promising strategy for the control of temperature. The 
advantage of the application of ESC is to be able to control the temperature in the cell using little prior knowledge about the process as well as having a better output disturbance rejection. Nowadays, most of the electrolysis processes are controlled by using PID controllers, which are usually not tuned correctly. In fact, PID controllers are suggested to be tuned using a model (Goodwin et al., 2000, p.160), and to do so, a deeper understanding of the process is required. Also, it is well-known that a PID controller cannot have, in general terms, good tracking and disturbance rejection simultaneously (Ogunnaike and Mukati, 2006).

The rest of the paper is organized as follows: In Section $\S 2$ we explain the electrolysis process used to obtain aluminium, in Section $\S 3$ we give motivation for the improvement of the current process. In Section $\S 4$ we explain the basic equations we have taken into account to model the cell bath. In Section $\S 5$ we briefly describe Extremum Seeking Control and its application to the aluminium electrolysis process. Finally, in Section $\S 6$ we draw conclusions of our work.

\section{ALUMINIUM OBTENTION: THE HALL-HÉROULT PROCESS}

The Hall-Héroult process is used to reduce bauxite (aluminium ore) to obtain pure aluminium. It was developed almost simultaneously in 1886 by the French Paul Héroult and the American Charles M. Hall. This process is now used all over the world and is the dominant method utilized in industry.

Aluminium is the most abundant metal on earth. However, due to contact with oxygen, it can only be found in the state of bauxite. The process of producing aluminium starts with the production of alumina $\left(\mathrm{Al}_{2} \mathrm{O}_{3}\right)$ from bauxite, where a large amount of coal and caustic soda is used. The next step in the production of aluminium is the use of electrolysis to obtain aluminium from alumina by the socalled Hall-Héroult process. This process takes place in a cell (pot) which is essentially a bath of molten cryolite (the electrolyte) and carbon electrodes. The process is basically governed by two main chemical reactions. The first one is the electro-chemical reaction in the electrolyte given by:

$$
\mathrm{Al}_{2} \mathrm{O}_{3}+1.5 \mathrm{C} \longrightarrow 2 \mathrm{Al}+1.5 \mathrm{CO}_{2},
$$

where carbon $(\mathrm{C})$ is fed to the reaction as anodes to be depleted. This reaction is called "primary reaction".

The melting point for alumina is around $2030\left({ }^{\circ} \mathrm{C}\right)$, hence requires a large amount of energy. In order to reduce the necessary energy required in the electrolysis, various compounds are added. Typically, these extra compounds include cryolite $\left(\mathrm{Na}_{3} \mathrm{AlF}_{6}\right)$, aluminium fluoride $\left(\mathrm{AlF}_{3}\right)$, sodium carbonate $\left(\mathrm{Na}_{2} \mathrm{CO}_{3}\right)$, and calcium fluoride $\left(\mathrm{CaF}_{2}\right)$. This allows the melting temperature of the electrolyte to be substantially lowered to around 1010 $\left({ }^{\circ} \mathrm{C}\right)$, mainly thanks to cryolite. The other additives can decrease the required temperature to approximately 960 $\left({ }^{\circ} \mathrm{C}\right)$ (Drengstig et al., 1998).

The energy consumption is lower if temperature can be maintained as low as possible and if $\mathrm{AlF}_{3}$ concentration in the cell can be held constant. However, in the process, $\mathrm{AlF}_{3}$ evaporates and therefore the concentration changes.
Hence, one way to maintain temperature as low as possible is by adding $\mathrm{AlF}_{3}$. The regulation of energy supplied to the process can be used as another manipulated variable helping to maintain the desired temperature in optimal ranges (Kolas and Store, 2009).

Another chemical reaction taking place in the process is due to the presence of carbon dioxide $\left(\mathrm{CO}_{2}\right)$. This chemical reaction is sparked by the reactivity of pure aluminium. This spontaneous reaction is given by

$$
2 \mathrm{Al}+3 \mathrm{CO}_{2} \longrightarrow \mathrm{Al}_{2} \mathrm{O}_{3}+3 \mathrm{CO},
$$

and is called "back reaction", which in fact converts aluminium back to alumina. This reaction reduces the efficiency in the cell.

Cryolite in the cell is very corrosive. The only compound capable to coexist with it is frozen cryolite, see Fig. 1. Hence, a crust of frozen cryolite needs to be maintained on the cell which has a double effect: it reduces the heat loss from the bath and the anode combustion and, it protects the side ledge of the bath from erosion. However, cryolite tends to lower the $\mathrm{pH}$. If the $\mathrm{pH}$ of the solution in the bath is too low, the main chemical reaction in (1) is not completely carried out by its stoichiometric equation.

To maintain the $\mathrm{pH}$ at desired levels another compound is added: aluminium fluoride $\left(\mathrm{AlF}_{3}\right)$. The $\mathrm{pH}$ of the solution is also directly related to the $\mathrm{AlF}_{3}$ concentration. Recall that the addition of $\mathrm{AlF}_{3}$ lowers the liquid temperature as well. Moreover, the presence of sodium oxide $\left(\mathrm{Na}_{2} \mathrm{O}\right)$ consumes $\mathrm{AlF}_{3}$ according to the following equation

$$
3 \mathrm{Na}_{2} \mathrm{O}+4 \mathrm{AlF}_{3} \longrightarrow 2 \mathrm{Na}_{3} \mathrm{AlF}_{6}+\mathrm{Al}_{2} \mathrm{O}_{3} \text {. }
$$

From the description above, we observe that the process is tightly interconnected between the different reactants taking place in the cell.

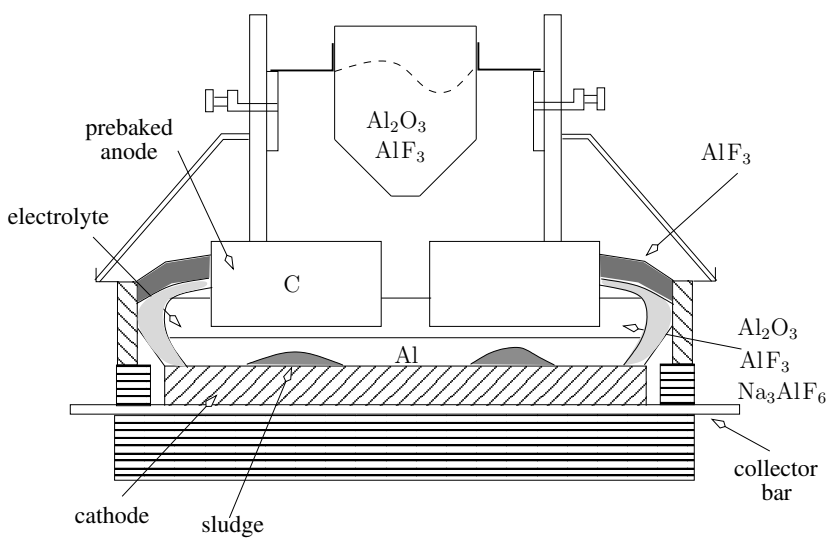

Fig. 1. Aluminium electrolysis prebaked cell taken from Drengstig et al. (1998).

\section{MOTIVATION TO IMPROVE THE PROCESS}

One of the main motivations to improve the process is energy saving. A typical cell voltage is 4.5 volts and the current is approximately $150(\mathrm{kA})$. A typical plant contains approximately 200 cells, having a power consumption of approximately 2.8 (MW.h $)^{1}$, which is a considerable

1 We consider an individual consumption of $14(\mathrm{~kW} . \mathrm{h})$ to produce $1(\mathrm{~kg})$ of aluminium in a prebaked cell 
energy consumption. This provides our motivation to improve the control of this kind of processes. Improving the process may be translated into the following actions:

- maintain bath temperature and acidity close to target at all times,

- maintain input power at the lowest possible level,

- minimize human intervention,

- avoid the use of soda and minimize the amount of added $\mathrm{AlF}_{3}$.

In this paper, we focus on the first action mentioned above to improve the process, that is, to maintain bath temperature and acidity close to target at all time.

If the temperature is too low, cryolite begins to freeze and the small anode-cathode distances increases the back reaction. Note that a small distance is necessary to reduce the bath temperature. If, on the other hand, the temperature is too high, the metal is very soluble and due to the presence of carbon dioxide $\left(\mathrm{CO}_{2}\right)$, the back reaction increases. An interesting note is that, in real plants, almost half of the cells spend their cycle outside the optimal temperature, therefore, having a poor level of efficiency. The relation between temperature and current efficiency (\%) can be seen in Fig. 2 (Grjotheim et al., 1982, pp.339$340)$. We observe that the "optimal" temperature would be around $960\left({ }^{\circ} \mathrm{C}\right)$.

The advantage of having a controlled temperature, and hence, reducing the variation of power consumption is that:

- power represents $30 \%$ of the plant costs, even a small reduction represents a large saving for companies,

- high power in the cell tends to melt their crust and side ledge,

- cells may produce metal contaminated with iron,

- the process of electrolysis can still be carried out, but with better energy consumption.

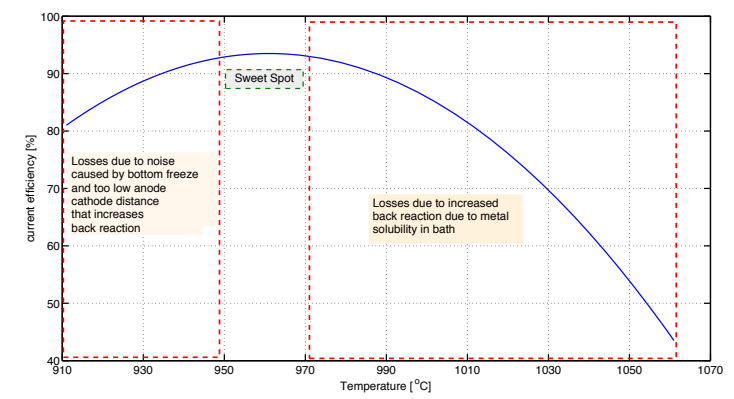

Fig. 2. Effect of varying temperature over the current efficiency.

\section{REDUCED MODEL OF THE PROCESS}

In this section, we briefly describe the model of the electrolysis cell used to simulate the plant, in particular, the part concerning the bath of the cell.

The purpose of this model is to apply our proposed control strategy, without having to evaluate it first in the actual plant. In that way, we can have a reasonable idea of the results, and the strategy may be applied to the actual process in later stages.
Our model of the electrolysis cell bath considers two sub-processes: i) the chemical reaction dynamics, and ii) temperature dynamics.

\subsection{Chemical reaction dynamics}

We model this sub-process making a number of simplifications. The first simplification is that we model it as a Continuous Stirred Tank Reaction (CSTR). The real process is, in fact, much more complex than a CSTR. However, this is a typical approach as described in Drengstig (1997).

The chemical reactions considered are in (1), (2) and (3). It is well-known (Luyben, 1990) that the dynamics of these chemical reactions can be written as:

$$
\begin{aligned}
& \dot{x}_{1}=D\left(u_{1}-x_{1}\right)-k_{1} x_{1} x_{2}+k_{2} x_{3} x_{4}+k_{3} C_{\mathrm{Na}_{2} \mathrm{O}} x_{6} \\
& \dot{x}_{2}=D\left(u_{2}-x_{2}\right)-k_{1} x_{1} x_{2} \\
& \dot{x}_{3}=-D x_{3}+2 k_{1} x_{1} x_{2}-2 k_{2} x_{3} x_{4} \\
& \dot{x}_{4}=-D x_{4}+1.5 k_{1} x_{1} x_{2}-3 x_{3} x_{4} \\
& \dot{x}_{5}=-D x_{5}+3 k_{2} x_{3} x_{4} \\
& \dot{x}_{6}=D\left(u_{3}-x_{6}\right)-4 k_{3} C_{\mathrm{Na}_{2} \mathrm{O}} x_{6},
\end{aligned}
$$

where $D=F_{i} / V$ is known as the dilution rate, $F_{i}$ is volume of the influx, $V$ the volume of the bath, and $x$ and $u$ defined as:

$$
\begin{aligned}
& x^{T}=\left[\begin{array}{llllll}
C_{\mathrm{Al}_{2} \mathrm{O}_{3}} & C_{\mathrm{C}} & C_{\mathrm{Al}} & C_{\mathrm{CO}_{2}} & C_{\mathrm{CO}} & C_{\mathrm{AlF}_{3}}
\end{array}\right],
\end{aligned}
$$

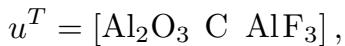

where $C_{k}$ represents the concentration of the respective reactant $k$. The reaction rates $k_{i}, i=1,2,3$ are taken in their standard manner, that is, $k_{i}=\alpha_{i} e^{-E_{i} / R T}$, where $E_{i}$ is the activation energy of each of the reactions, $T$ is the absolute temperature (in Kelvin degrees), and $R$ is the ideal gas constant.

We have assumed a constant concentration of $\mathrm{Na}_{2} \mathrm{O}$ and $\mathrm{Na}_{3} \mathrm{AlF}_{6}$. Hence, these components are not considered to change in the dynamic equations for the chemical reactions. Also, we assume a constant feed of $\mathrm{Al}_{2} \mathrm{O}_{3}$. As we mentioned above, $\mathrm{Al}_{2} \mathrm{O}_{3}$ control can be considered as a separate problem, therefore, we assume it be a constant for the chemical reaction dynamics.

\subsection{Temperature dynamics}

In the electrolysis cell, we have basically three sources to consider for the temperature dynamics, namely, i) the temperature generated by the electrolysis process, ii) the temperature dissipated (convection and conduction) through the walls of the electrolysis cell, and iii) the temperature generated by the endothermic (and exothermic) chemical reactions. We label each of these terms as: $Q_{i}, Q_{w}$ and $Q_{q r}$, respectively.

The first term $Q_{i}$ (see Drengstig et al., 1998) can be expressed as $Q_{i}=R_{\text {bath }} I_{\text {cell }}^{2}$. The second term $Q_{w}$ can be directly taken from Drengstig (1997), that is,

$$
Q_{w}=\frac{A_{w}}{1 / h+l_{w} / k_{w}}\left(T_{\text {bath }}-T_{\text {ext }}\right),
$$

where $A_{w}$ is the area of the cell wall, $l_{w}$ is the length/thickness of the wall, $h$ is the heat transfer coefficient, $T_{\text {bath }}$ is the temperature in the cell bath, and $T_{\text {ext }}$ is the external temperature to the cell. 
The final term, $Q_{q r}$, is due to the chemical reactions. From Luyben (1990) we have:

$$
\rho \bar{C}_{p} \frac{d(V T)}{d t}=\rho \bar{C}_{p}\left(F_{i} T_{i}-F T\right)+Q_{i}-Q_{w}-\sum_{k} Q_{q r_{k}}
$$

where $\bar{C}_{p}$ is an average heat capacity (of the cell bath), $\rho$ is the density of the bath, and $Q_{q r_{k}}$ is the heat absorbed (or generated) by the chemical reaction $k$ in the cell, (1), (2) and (3). We model the cell bath at a stationary volume, i.e. we have $F_{i}=F$. From (7) we have

$$
\rho \bar{C}_{p} V \frac{d T}{d t}=\rho \bar{C}_{p} F_{i}\left(T_{i}-T\right)+Q_{i}-Q_{w}-\sum_{k} Q_{q r_{k}},
$$

where $\rho \bar{C}_{p} V$ can be approximated as

$$
\rho \bar{C}_{p} V \approx V \sum_{k} \bar{C}_{p_{k}} C_{k} W_{k},
$$

and where $\bar{C}_{p_{k}}, C_{k}$ and $W_{k}$ are the heat capacity, concentration, and molecular weight of each compound $k$ in the cell bath, respectively. Each chemical reaction absorbing (or generating) heat in (8) can be expressed as:

$$
\begin{aligned}
& Q_{q r_{1}}=\lambda_{1} k_{1}(T) V x_{1} x_{2}, \quad Q_{q r_{2}}=\lambda_{2} k_{2}(T) V x_{3} x_{4}, \\
& Q_{q r_{3}}=\lambda_{3} k_{3}(T) V C_{\mathrm{Na}_{2} C} x_{6},
\end{aligned}
$$

where we have adopted the convention that $\lambda_{i}$ is positive for endothermic reactions, and negative for exothermic ones.

The nomenclature used in the model can be found in the following table:

Table 1. Nomenclature.

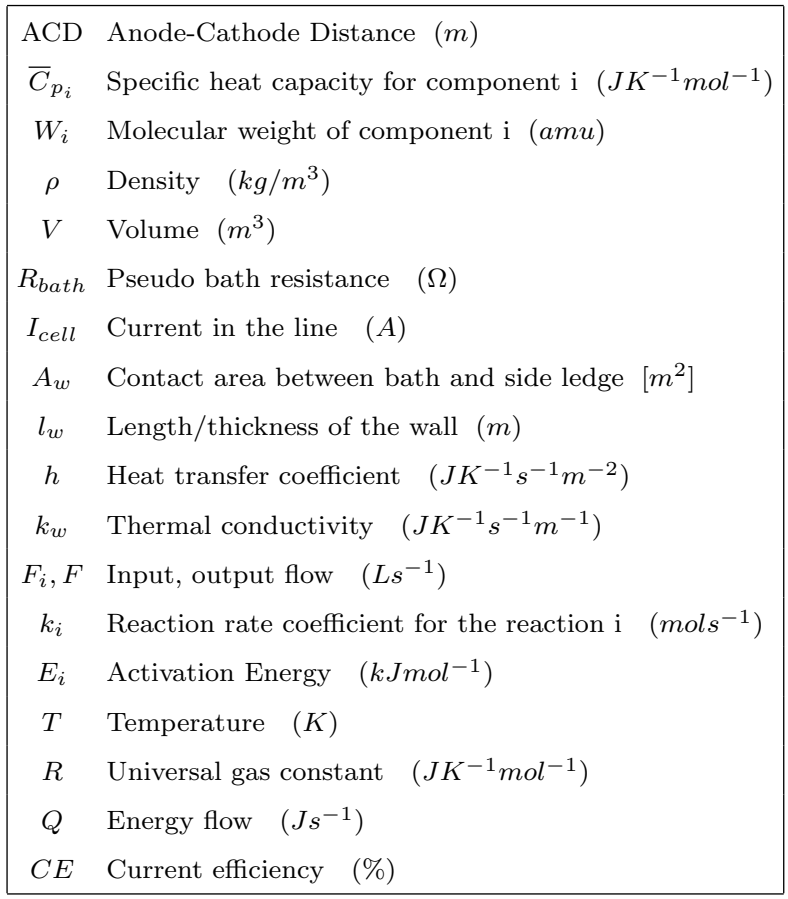

\section{EXTREMUM SEEKING CONTROL}

\subsection{Overview}

Extremum Seeking Control (ESC) is an adaptive feedback control strategy that can be applied without the need of a model to an important class of nonlinear control problems (Ariyur and Krstić, 2003). The goal of this control strategy is to drive an observable system output or objective cost to an optimal extremum value by use of adaptive feedback.

Fig. 3 shows a typical discrete-time scheme implementation structure of an ESC strategy. The plant is a stable (or stabilisable) nonlinear system assumed to be represented by state equations of the form

$$
x_{k+1}=f\left(x_{k}, u_{k}\right), \quad y_{k}=h\left(x_{k}\right),
$$

where $x_{k} \in \mathbb{R}^{n}$ is the state, $u_{k} \in \mathbb{R}$ is the input, $y_{k} \in \mathbb{R}$ is the output, and $f, h$ are smooth functions, not necessarily known for the implementation of ESC.

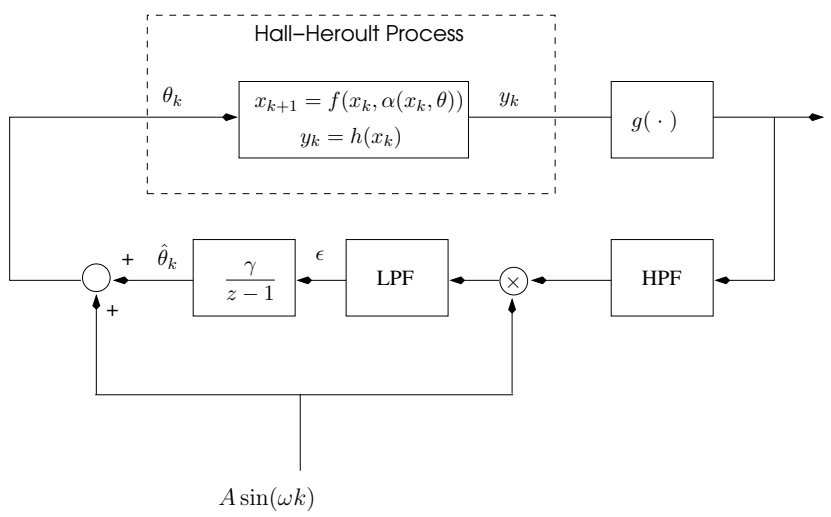

Fig. 3. ESC scheme applicable to temperature control in the Hall-Héroult process.

ESC implements real-time optimisation using the observed output $y_{k}$ to estimate and drive the gradient of the objective cost to zero by imposing a probing (oscillatory) behaviour in the system to seek and maintain the optimising input, $u^{\mathrm{opt}}$.

One key assumption for the nonlinear system to be controlled by ESC is that it has an extremum in the map between the input $u_{k}$ and the output $y_{k}$ (Ariyur and Krstić, 2003, Chap. 5). If that extremum exists, then an external sustained excitation, $\left(A \sin \omega_{k}\right)$ in Fig. 3, is used to find the extremum value of the system output by perturbing the system around its operating point. The frequency of this behaviour needs to be of a faster time scale than that of the dynamics of the operating point, which is then gradually driven to its optimal value.

It is worth to note that the control input $u_{k}$ may be, in general, a function of the state $x_{k}$ and a parameter $\theta_{k}$, as shown in Fig. 3. We will consider the simplified case of a control law not directly dependent on the system state, that is, $u_{k}=\theta_{k}$. Hence, the closed loop equation for the system (11) is given by

$$
x_{k+1}=f\left(x_{k}, \theta_{k}\right) .
$$

where $\theta_{k}$ is slowly driving the system operating point.

\subsection{Control of Temperature and Acidity}

To control this process, we need to define what outputs of the system are important, and with what inputs we can modify the outputs of interest. This has been established in other works, see e.g. Kolas and Store (2009). We note that the cell has the following outputs: Temperature in the 
bath, $\mathrm{AlF}_{3}$ concentration and $\mathrm{Al}_{2} \mathrm{O}_{3}$ concentration (Kolas and Store, 2009) denoted by $T^{o},\left[\mathrm{AlF}_{3}\right]$ and $\left[\mathrm{Al}_{2} \mathrm{O}_{3}\right]$, respectively. On the other hand, we can find the following inputs: anode beam adjustment (energy input), addition of $\mathrm{AlF}_{3}$, and addition of $\mathrm{Al}_{2} \mathrm{O}_{3}$. Notice that the beam adjustment to control temperature in the cell is translated into the adjustment of the anode-cathode distance (ACD). In fact, each ACD is associated with a certain amount of energy being proportional to ACD.

In this work, we focus on temperature control in the bath of the cell and the control of $\left[\mathrm{AlF}_{3}\right]$. We do not consider the control of $\left[\mathrm{Al}_{2} \mathrm{O}_{3}\right]$ as part of this problem. The control of $\left[\mathrm{Al}_{2} \mathrm{O}_{3}\right]$ can be considered as an isolated control problem (Kolas and Store, 2009).

A logical way to control this process is by keeping a tight control of the temperature and, at the same time, having a constant addition of $\mathrm{AlF}_{3}$. However, this strategy may lead to wind-up problems if not done properly (Kolas and Store, 2009). Hence, it seems better to have a strategy controlling $\left[\mathrm{AlF}_{3}\right]$ and temperature at the same time, especially if we have a strong intercoupling between temperature and acidity.

\subsection{Application of ESC to the Aluminium process}

In the aluminium process, as shown in Fig. 2, an extreme in efficiency arises with respect to temperature making the aluminium process a good candidate for ESC. It is known that an optimal temperature will make the process more efficient with respect to energy consumption. As we can see in Fig. 2, an excess of temperature tends to make the process less efficient. On the other hand, cooling down the electrolysis process will make the process less efficient.

We use the scheme shown in Fig. 3, and evaluate it by simulations using a model of the actual plant. In Fig. 3, we notice that there is a function $g(\cdot)$ at the output of the process. This function is defined as the negative quadratic norm of the difference between $y_{k}$ (temperature) and the reference $\bar{y}$, that is, $g=-\left\|y_{k}-\bar{y}\right\|_{2}$. The purpose of this function is to force the model of the process to have a maximum at a pre-specified temperature (reference). In doing so, we assure that the temperature reaches a value close to the "optimal" value, that is, the value which gives the best current efficiency as shown in Fig. 2.

The implementation of ESC requires design of the input excitation signal, with parameters $A$ and $\omega$, and the cutoff frequency $\omega_{H F}$ for the high-pass filter (HPF). The lowpass filter (LPF) is not strictly necessary, and was not used in the present implementation. These parameters are chosen as follows (Godoy et al., 2008)

- Frequency of the exciting signal, $\omega$ : the frequency of the exciting signal should be chosen large, however, this frequency should not be greater than the dominant pole of the system. Otherwise, the system is unable to follow the input. The dynamics of the system using the anode-cathode distance (ACD) as the input and bath temperature as the output is dominated by a frequency $f_{o} \approx 0.33\left[\right.$ day $\left.^{-1}\right]$, hence, we choose $\omega \leq 2 \pi f_{o}$, and in particular $\omega=0.1[\mathrm{rad} /$ day $]$.

- Amplitude of the exciting signal, $A$ : the amplitude of the exciting signal should be chosen small as compared to the nominal value of the output, in order to obtain a small steady state output error. We select it as $A=0.1$.

- Cut-off frequency of the high-pass filter, $\omega_{H F}$ : the cut-off frequency of this filter is chosen after a sensitivity analysis using 3 frequencies: $\omega_{H F}=$ $\{0.01 \omega, 0.05 \omega, 0.1 \omega\}$. The result is shown in Fig. 5 . We can observe that, in general, good results are obtained when a cut-off frequency for the filter is $\omega_{H F}=0.1 \omega$. We observe that the control signal (ACD) has very little oscillation, which is the purpose of the adjustment of this filter.

- Gain $\gamma$ : without loss of generality, this value is chosen $\gamma=1$.

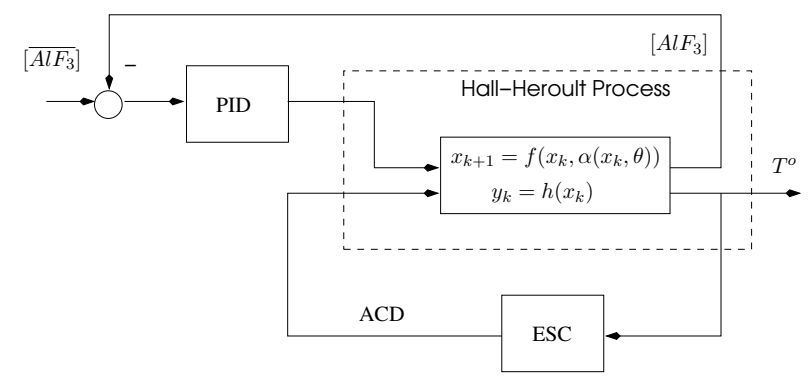

Fig. 4. General configuration applying ESC scheme to the Hall-Héroult process to control temperature, and PID control of $\mathrm{AlF}_{3}$ concentration $\left(\left[\mathrm{AlF}_{3}\right]\right)$.

The control strategy to be used on the model of the process is then ESC applied to the temperature of the bath, and a PID controller applied to control the acidity of the bath. Both variables must be controlled at the same time. The advantage of the proposed control strategy is to control temperature using ESC, with little a-priori knowledge about the temperature dynamic model. The control configuration is shown in Fig. 4.
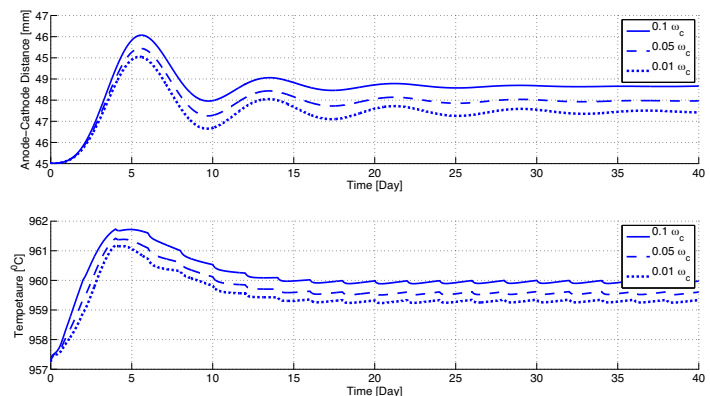

Fig. 5. Effect of varying cut-off frequency for the high-pass filter used in the ESC scheme.

The results of the simulations are shown in Fig. 6, for the controlled output temperature and acidity. We can observe that the application of ESC to this process meets the requirements we have imposed, that is, to have the temperature operating around optimal ranges with little oscillation. The control of acidity, on the other hand, is good, reaching a stationary state in a short period of time. We acknowledge, however, that similar results might be found using PID adjustment, but at a higher price in terms of temperature modelling. 

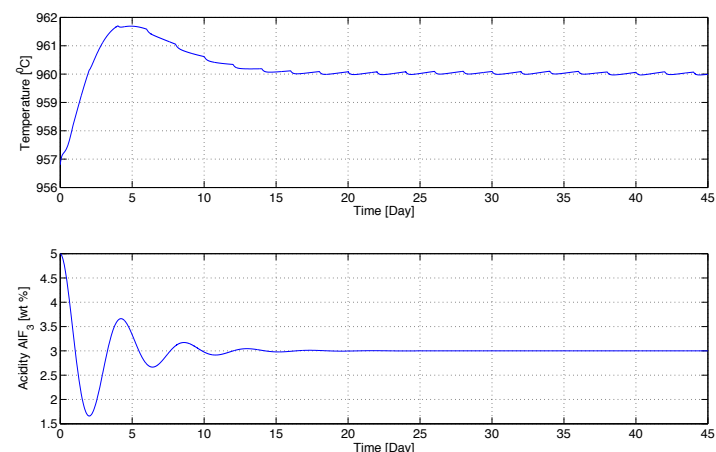

Fig. 6. Effect on the Control of temperature (upper plot) and effect on control of $\left[\mathrm{AlF}_{3}\right]$ (lower plot) using ESC in temperature, and a PID controller for acidity.

One important characteristic of ESC is the improved output disturbance compensation as compared to PID control. This is clear from the scheme shown in Fig. 3, where ESC will take care of every output disturbance below the cut-off frequency of the filter $\omega_{H F}$. This is not achievable by using a PID to control the temperature dynamics because of the compromise between tracking and disturbance compensation. The response of the controlled variables to step-like output disturbances in temperature and acidity can be observed in Fig. 7 .
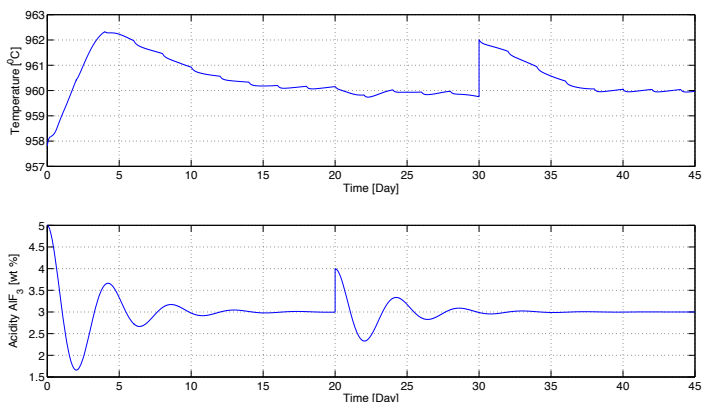

Fig. 7. Disturbance rejection of the proposed ESC-PID strategy to : i) acidity step-like disturbance at $t=20$ [days], and ii) Temperature step-like disturbance at $t=30$ [days].

\section{CONCLUSIONS}

In this paper, we have investigated the application of ESC for the feedback control of temperature in an aluminium electrolysis cell as well as the development of a simplified model of the electrolysis bath. Simulation results are promising as good control of the temperature and acidity using a mixed approach of ESC (for temperature in the bath) and PID controller (for the acidity in the bath) was obtained.

The ESC method has been applied to a model of the aluminium plant, which was developed from first principles. We acknowledge that the model may not be a complete representation of a real plant, but the configuration proposed (model and ESC) gives a clear indication of the potential of ESC applied to this kind of processes, in particular, the aluminium electrolysis cell.

\section{REFERENCES}

Ariyur, K. and Krstić, M. (2003). Real-Time optimization by Extremum Seeking Control. Wiley-Interscience.

Blackman, P. (1962). Exposition of Adaptive Control, chapter Extremum Control Regulators. The McMillan Company, New York, NY.

Desclaux, P. (1987). AlF 3 additions based on bath temperature measurements. Light Metals, 309-313.

Drengstig, T. (1997). On Process model representation and $\mathrm{AlF}_{3}$ dynamics of aluminium electrolysis cell. Ph.D. thesis, Norwegian Univ. of Science and Tech. (NUST).

Drengstig, T., Ljungquist, D., and Foss, B. (1998). On the $\mathrm{AlF}_{3}$ and temperature control of an aluminium electrolysis cell. IEEE Trans. on Control Syst. Tech., $6(2), 157-171$.

Dwight, J. (1999). Aluminium design and construction. E\& FN Spon, London.

Godoy, B.I., Braslavsky, J.H., and Agüero, J.C. (2008). A simulation study on Model Predictive Control and Extremum Seeking Control for heap bioleaching processes. In IFAC World Congress. Seoul, Korea.

Goodwin, G., Graebe, S., and Salgado, M. (2000). Control System Design. Prentice Hall.

Grjotheim, K., Krohn, C., Malinovsky, M., Matiasovsky, K., and Thonstad, J. (1982). Aluminium Electrolysis. Aluminium-Verlag.

Guay, M. and Zhang, T. (2003). Adaptive extremum seeking control of nonlinear dynamic systems with parametric uncertainties. Automatica, 39(7), 1283-1293.

Kolas, S. and Store, T. (2009). Bath temperature and al $f_{3}$ control of an aluminium electrolysis cell. Control Eng. Practice, 17, 1035-1043.

Luyben, W.L. (1990). Process modeling, simulation, and control for chemical engineers. McGraw-Hill, New York.

Ogunnaike, B.A. and Mukati, K. (2006). An alternative structure for next generation regulatory controllers Part I: Basic theory for design, development and implementation. Journal of Process Control, 16, 499-509.

Salt, D.J. (1990). Batch chemistry control system. Light Metals, 299-304. 